\title{
Isolated duodenal rupture due to blunt abdominal trauma
}

\author{
Atilla Celik, Ediz Altinli, Ender Onur, Aziz Sumer, Neset Koksal
}

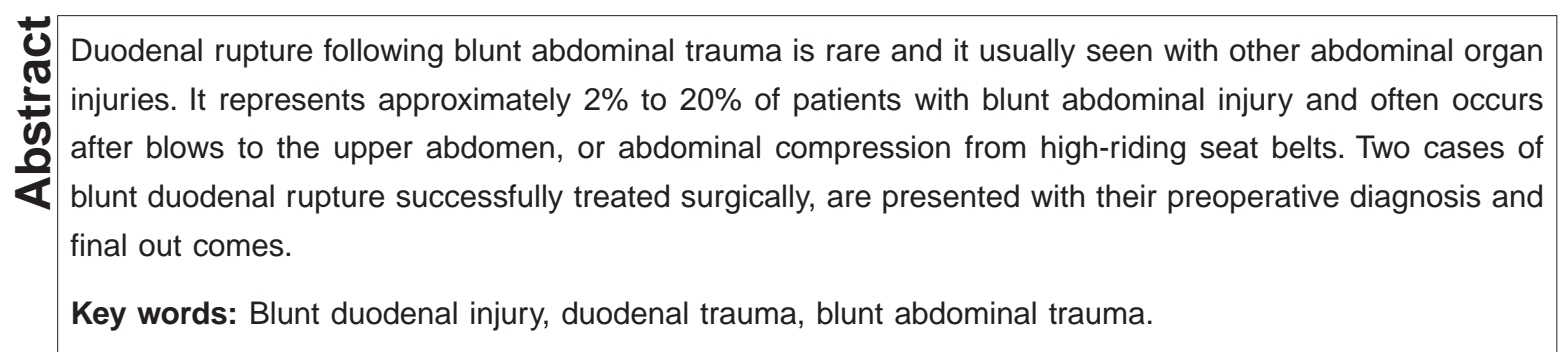

Duodenal rupture following blunt abdominal trauma is rare and it is usually seen with other abdominal organ injuries. It represents approximately $2 \%$ to $20 \%$ of patients with blunt abdominal injury and often occurs after blows to the upper abdomen, or abdominal compression from high-riding seat belts. ${ }^{[1]}$ Forty percent of patients with duodenal injuries have other concomitant surgically important intra-abdominal injuries, such as hepatic $(38 \%)$, or pancreatic $(28 \%)$ injuries. ${ }^{[2]}$

\section{Case 1}

A healthy 14 year old male was admitted to the emergency department with blunt abdominal trauma, after a traffic accident.

Physical examination on admission showed slightly tender abdomen and two epigastric dermabrasion, with $2 \times 2 \mathrm{~cm}$ in dimensions. Blood pressure, pulse and temperature, were all normal. Blood analysis showed a

\section{From:}

Haydarpasa Numune Training and Research Hospital, Department of General Surgery, $2^{\text {nd }}$ General Surgery Clinic, Istanbul, Turkey

\section{Correspondence:}

Dr. Ediz Altinli, Naci Kasim Cad. Baran Sitesi C 1 Blok D: 10, 34590

Bahcelievler, Istanbul, Turkey. E-mail: dredizaltinli@yahoo.co.uk hemoglobin $12.6 \mathrm{~g} / 100 \mathrm{ml}$, a white blood cell count of $23 \times 10 \% / \mathrm{L}$ and amylase level of $126 \mathrm{mg} / 100 \mathrm{ml}$.

Plain abdominal and chest radiographs were normal and did not show any evidence of pneumoperitoneum and abdominal ultrasonography were unremarkable. The patient was admitted for observation. After observation for 2 hours, the patient had prominent peritoneal signs and a hollow viscus injury was suspected. IV contrast enhanced computed tomography (CT) scanning without oral contrast material was performed, which revealed retroduodenal and perirenal air [Figure 1]. The patient underwent urgent laparotomy for duodenal rupture, with initial diagnosis. The injury severity degree evaluated to grade III, according to duodenal injury scale as described by Moore et al. ${ }^{[3]}$ Primary repair plus drainage was the choice of treatment. Recovery after the operation was uneventful and the patient were discharged from hospital on the $6^{\text {th }}$ postoperative day.

\section{Case 2}

A 52 year old cycle driver was admitted to the emergency department with epigastric abdominal pain, because of striking to the abdomen by the handlebar of the bike, during falling. 


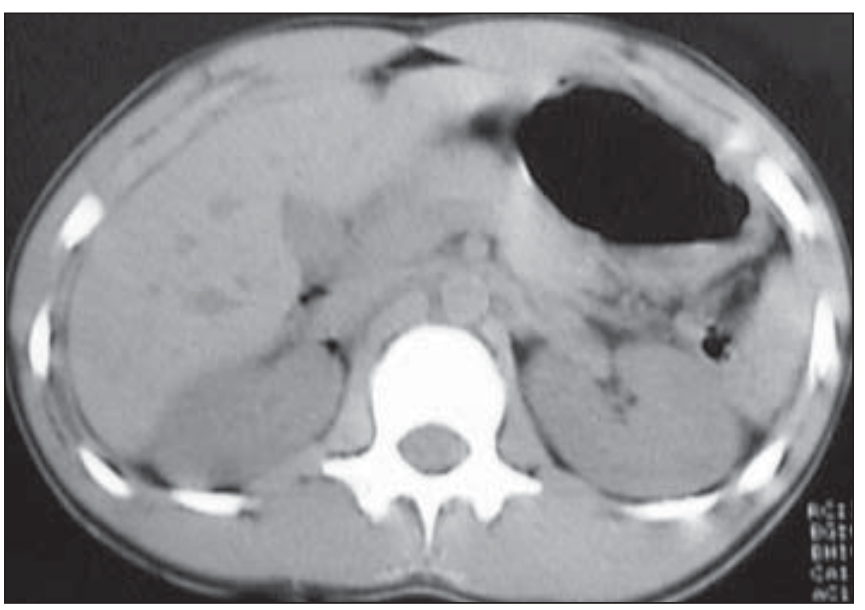

Figure 1: (CT) scanning revealed retroduodenal and perirenal air.

First observations including blood pressure, pulse and temperature, were all normal. Abdominal examination was not special, except for epigastric echimosis with 2 $\mathrm{cm}$ in diameter, due to hitting of the handlebar. Blood analysis showed a hemoglobin level at $13 \mathrm{~g} / 100 \mathrm{ml}$ and a white blood cell count of $13 \times 10^{9} / \mathrm{L}$. Serum amylase was $147 \mathrm{mg} / 100 \mathrm{ml}$. Abdominal plain roentgenograms and abdominal ultrasonography were normal. Because of persistent pain and suspicion of abdominal injury, IV contrast enhanced abdominal CT scanning without oral contrast material, was performed. The CT demonstrated retroperitoneal air, especially in the prevertebral area and anterior of the iliopsoas muscle [Figure 2]. The patient underwent urgent laparotomy with diagnosis of duodenal rupture, like the first patient. The injury severity degree evaluated to grade III, according to the duodenal injury scale as described by Moore et al. ${ }^{[3]}$ The rupture site was the anterior and posterior site of the $3^{\text {rd }}$ part of the duodenum. Primary repair in a shape of Henike-Mickulich

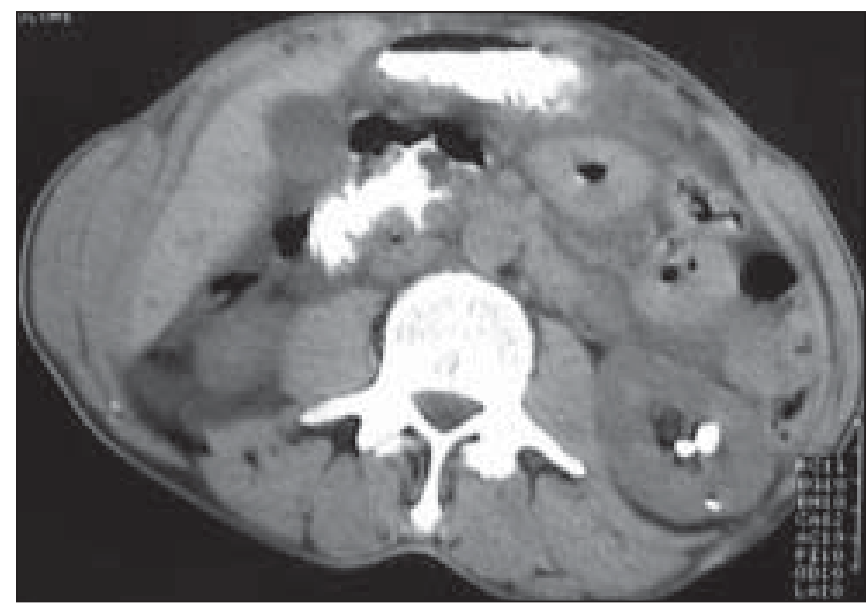

Figure 2: CT revealed retroperitoneal air especially at the prevertebral and anterior of the right perirenal area. type plus drainage was the choice of treatment.Recovery after the operation was uneventful and the patient was discharged from hospital on the $12^{\text {th }}$ postoperative day.

\section{Discussion}

Isolated blunt injury of the duodenum is both less common and more difficult to diagnose than penetrating injuries and it may also occur with pancreatic injury. ${ }^{[4]}$ Despite progression of the imaging techniques, the diagnosis still remains critical and may be delayed in particular, when there is perforation of the retroperitoneal part of the duodenum. ${ }^{[5]}$

It usually occurs from crushing of the duodenum between the spine and steering wheel, handlebar, or some other force applied to the anterior aspect of the abdomen. ${ }^{[6]}$

While the history and clinical findings of steering wheel, handlebar and seat belt marks on the anterior abdominal wall may make the clinician suspect a duodenal injury, the physical examination may not be helpful in trying to identify early duodenal injuries. ${ }^{[7]}$

In the vast majority of retroperitoneal perforations, there is at first only mild upper abdominal tenderness with a progressive rise in temperature, tachycardia and occasional vomitting. After several hours, the duodenal contents extravasate into the peritoneal cavity, with the development of peritonitis. Initial clinical changes in isolated duodenal injury may be extremely subtle before the severe, life-threatening, peritonitis develops. ${ }^{[4]}$

Laboratory findings that contain WBC, hemoglobin, or amylase level, are not specific. Although serial determination of serum amylase is better than a single, isolated assay on admission, sensitivity is still low and serial determination involves unnecessary delay in the treatment.

Plain radiographs of the abdomen are useful when gas bubbles are present in the retroperitoneum. They may also show free intra-peritoneal gas and, although rarely seen, gas in the biliary tree has also been described. ${ }^{[8]}$

Abdominal ultarsonograpy is faster and less invasive than diagnostic peritoneal lavage and can occasionally 
reveal injuries in the retroperitoneum. Abdominal sonography that reveals free fluid, suggests hemoperitoneum, or bowel injury requires abdominal CT or emergency laparotomy. ${ }^{\left[{ }^{[9]}\right.}$

Diagnostic peritoneal lavage (DPL) has been found to have a low diagnostic sensitivity for duodenal rupture, because of the retroperitoneal location of the duodenum. Furthermore, because the incidence of associated intra abdominal injuries is high in cases of duodenal trauma and liver or splenic injury is often the source of a positive DPL, so the specificity of DPL for duodenal rupture remains still low. ${ }^{[10]}$

CT has been added to the diagnostic algorithm for subtle duodenal injury. It is very sensitive to the presence of small amounts of retroperitoneal air, blood, or contrast agent extravasated from the injured duodenum, especially in children. ${ }^{[4]}$

Early diagnosis of duodenal rupture is essential, the delay of which is associated with increased morbidity and mortality. The diagnosis of this injury remains problematic, because the signs and the symptoms of retroperitoneal viscus are notoriously subtle.

Diagnostic delaying of the patients with duodenal rupture may cause catastrophic events. A delay in diagnosis for longer than 24 hours results in a thickened, friable and inflamed bowel wall. Primary repair alone is unlikely to be successful, as it may lead to duodenal dehiscence, a lateral duodenal fistula and other lethal complications. ${ }^{[7]}$

The degree of duodenal injury, diagnosis time and surgeon preference,often determines the type of technique using repair. Although most duodenal injuries can be managed successfully by simple repair, the available techniques contain simple reparation, tube duodenostomy and pyloric exclusion, with or without gastrojejunostomy. ${ }^{[11]}$

In conclusion, the diagnosis of duodenal injuries remains difficult, with high incidence of suspicions, especially if it is isolated. A preoperative diagnosis of isolated duodenal rupture can be very difficult to make and there is no single method of duodenal repair that completely eliminates the possibility of dehiscence of the duodenal suture line. ${ }^{[4]}$

Contrast enhanced abdominal CT may be helpful for early diagnosis and to prevent complications due to delayed diagnosis of duodenal rupture.

\section{References}

1. Yutan E, Waitches GM, Karmy-Jones R. Blunt duodenal rupture: complementary roles of sonography and CT. Am J Roentgenol 2000;175:1600.

2. Jurkovich GI. Injury to the duodenum and pancreas. In: Feiciano DV, Moore EE, Mattox KL, editors. Trauma, $3^{\text {rd }}$ ed. Appleton \& Lange: Stamford, CT; 1996. p. 573-694.

3. Moore EE, Cogbill TH, Malagoni MA, Jurkovich GI, Champion HR, Gennarelli TA, et al. Organ injury scaling, II: Pancreas, duodenum, small bowel, colon and rectum. J Trauma 1990;30:1427-9

4. Degiannis E, Boffard K. Duodenal injuries. Br J Surg 2000;87:1473-9.

5. Champault A, Roudie J, Smadja C. Traumatic duodenal necrosis with peri-ampullary duodenal detachment. J Pediatr Surg 2004;39:1136-7.

6. Fang JF, Chen RJ, Lin BC, Hsu YB, Kao JL, Kao YC, et al. Retroperitoneal laparostomy: an effective treatment of extensive intractable retroperitoneal abscess after blunt abdominal trauma. J Trauma 1999;46:652-5.

7. Fang JF, Chen RJ, Lin BC. Surgical treatment and outcome after delayed diagnosis of blunt duodenal injury. Eur J Surg 1999;165:133-9

8. Ivatury RR, Nassoura ZE, Simon RJ, Rodruigez A. Complex duodenal injuries. Surg Clin North Am 1996;76:797-812.

9. Mindelzum RE, Jeffrey RB Jr. The acute abdomen: Current imaging techniques. Semin Ultrasound CT MR 1999;20:63-7.

10. Ballard RB, Badellino MM, Eynon CA, Spott MA, Staz CF, Buckman RF Blunt duodenal rupture: A 6-Year statewide experience. J Trauma 1997;43:229-32.

11. Ladd AP, West KW, Rouse TM, Scherer LR, Rescorla FJ, Engum $\mathrm{SA}$, et al. Surgical management of duodenal injuries in children. Surgery 2002;132:748-53. 